\title{
EDGE CORRECTION IN THE DETERMINATION OF DIELECTRIC CONSTANT
}

\author{
By Arnold H. Scott and Harvey L. Curtis
}

\section{ABSTRACT}

An edge correction is often required in determining the dielectric constant of an insulating material by the capacitance method. Theoretical formulas by which the edge correction may be computed have been considered for a number of electrode arrangements. Some of these apply to circular electrodes and some to rectangular electrodes. The error in the dielectric constant which may arise from the use of these formulas is discussed for each of the different arrangements.

The accuracies of the methods were experimentally determined by making measurements on the same specimens with the various arrangements of electrodes. The guard-ring arrangement was assumed to give the correct value of the dielectric constant, and the values obtained with the other arrangements were compared with it to determine their errors. Only two methods gave values which were in error by less than 1 percent. Both methods were for arrangements of electrodes in which one electrode was smaller than the other, one being for circular electrodes, the other for rectangular electrodes.

Empirical equations were set up which gave values of the dielectric constant which were in error by less than 1 percent for all electrode arrangements, both for circular and rectangular electrodes. These equations are much simpler than the theoretical equations.

\section{CONTENTS}

\section{Part 1. Theoretical Determination of Edge Correction}

I. Introduction

II. Theory of edge correction with a single sheet of dielectric

1. Edge correction for circular electrodes _... . . . . . . 750

(a) Theoretical formula when a circular sheet of dielectric has electrodes of the same diameter as the sheet...- 751

(b) Theoretical formula when a sheet of dielectric has one large electrode and one small circular electrode_._._ 752

(c) Theoretical formula when a sheet of dielectric extends beyond the circumferences of the electrodes_....... 753

(d) Elimination of the edge correction for circular electrodes by using a guard electrode_...

2. Edge correction for rectangular electrodes_.............. 754

(a) Theoretical formula when a rectangular sheet of dielectric has electrodes covering both faces _....... 755

(b) Theoretical formula when a sheet of dielectric has one large electrode and one small rectangular electrode _. 755

(c) Theoretical formula when a sheet of dielectric extends beyond the edges of rectangular electrodes _...... 756

(d) Elimination of the edge correction for rectangular electrodes by using a guard electrode.......... 756 
III. Theory of edge correction with two sheets of dielectric

1. Edge correction for circular electrodes .

(a) Theoretical formula when the two sheets of dielectric and the electrodes have the same diameter.......... 757

(b) Theoretical formula when the outer electrodes and the two sheets of dielectric extend beyond the circumference of the center electrode

(c) Theoretical formula when the two sheets of dielectric extend beyond the circumferences of the electrodes... 759

2. Edge correction for rectangular electrodes._.

(a) Theoretical formula when the outer electrodes and the two sheets of dielectric extend beyond the perimeter of the center electrode.

Part 2. Experimental Determination of the Edge Correction

I. Introduction

II. Arrangement of electrodes

III. Electrical measurements

IV. Results

1. Test of Kirchhoff's equation

2. Dielectric constants when theoretical equations were used _._... 764

(a) Circular electrodes

(b) Rectangular electrodes

3. Determination of empirical equations

4. Dielectric constants when empirical equations were used.

V. Summary _...

\section{PART 1. THEORETICAL DETERMINATION OF EDGE CORRECTION}

\section{INTRODUCTION}

An edge correction is usually required in those capacitance methods of determining dielectric constant that employ only two electrodes. This necessity arises from the difficulty of making the experimental conditions of a method conform to the requirements implied in the definition of dielectric constant. The dielectric constant of a material is defined as the ratio of the capacitance of a capacitor having the material as a dielectric to the capacitance of another capacitor which has an identical arrangement of electrodes, but has a vacuum as the dielectric. This may conveniently be represented by the equation

where

$$
K=\frac{C_{k}}{C_{\bullet}}
$$

$K=$ the dielectric constant of the material,

$C_{k}=$ the capacitance of a capacitor, with the material as its dielectric, and

$C_{v}=$ the capacitance of a capacitor having an identical arrangement of electrodes as for $C_{k}$, but having a vacuum ${ }^{1}$ as its dielectric.

This definition assumes that, for each capacitor, the dielectric completely fills the electric field surrounding the electrodes. When the dielectric does not completely fill the electric field, there must be applied to $\mathrm{C}_{k}$ a correction which is commonly called the edge correction.

\footnotetext{
${ }^{1}$ Except for measurements of high precision, air, having a dielectric constant of 1.00059 under normal con-
} ditions, may be used instead of a vacuum. 
The principal application of the edge correction is in determining the dielectric constant of solids in the form of sheets. A capacitor is constructed from a sheet of the material by placing an electrode on each side. The capacitance of this capacitor is measured, and the capacitance of a capacitor which is identical, except that it has vacuum as a dielectric, is computed. The edge correction is introduced to correct the measured capacitance for the reason that the dielectric under investigation does not completely fill the electric field surrounding the electrodes, and to give an accurate formula for determining the computed capacitance. To avoid the necessity of applying an edge correction, a capacitor having a guard electrode is often employed. In many cases, however, the use of a guard electrode is not feasible, so that a method involving an edge correction is necessary.

Six different arrangements of circular electrodes, besides the one using a guard electrode, are considered. Three of these and the guardelectrode arrangement apply to a single sheet of material with electrodes on opposite sides. Three other arrangements apply to a pair of sheets with one electrode between them and with their outer electrodes joined to form a single electrode. Five arrangements of rectangular electrodes are discussed. Three of these and the guard-electrode arrangement apply to a single sheet of material. Only one arrangement, using two sheets of material, has been investigated for rectangular electrodes.

\section{THEORY OF EDGE CORRECTION WITH A SINGLE SHEET OF DIELECTRIC}

A sheet of dielectric material is prepared for the determination of its dielectric constant by placing electrodes on its two opposite faces. The electrode may completely cover the two faces of the sheet, or one or both electrodes may be smaller than the sheet. Each such arrangement constitutes a capacitor, the capacitance of which can be measured by comparison with a standard capacitor or by some other suitable method. However, the measured capacitance may include the capacitance between one or both electrodes and the earth. The contribution of this earth capacitance depends on the connection to earth of the

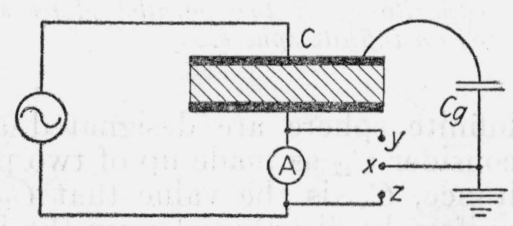

FIGURE 1.-Diagram showing the effect on the measured capacitance of changing the point at which the ground connection is made.

measuring circuit. Even with one electrode at earth potential, a change in the connection to earth may change the measured capacitance. This is illustrated by the diagram of figure 1, in which it is indicated that an ungrounded alternating potential is impressed on the plates of a capacitor, and the current in the circuit is measured by the ammeter, $A$. If the alternating potential has a definite value and frequency, the capacitance is proportional to the reading of the ammeter, $A$. If the ammeter has a negligible impedance relative to that of the capacitor, the lower plate of the capacitor will be at earth potential when the earth connection is made on either side of the ammeter. If the connection is below the ammeter ( $x$ connected to $z$ ), the measured current is that through $C$ only, while if the connection is above the ammeter ( $x$ connected to $y$ ), the measured current is that through both 
$C$ and $C_{a}$ (capacitance to earth). The following discussion refers to those cases in which $C$ only is measured. If the measuring circuit is so arranged that $C_{g}$ is included in the measurement, then the following equations will have to be modified to include $C_{g}$, the value of which will depend on the proximity of surrounding objects and will have to be determined for each setup.

Although the experimental arrangement is assumed to be such that only the capacitance between the electrodes is measured, yet the theoretical discussion will be simplified by considering

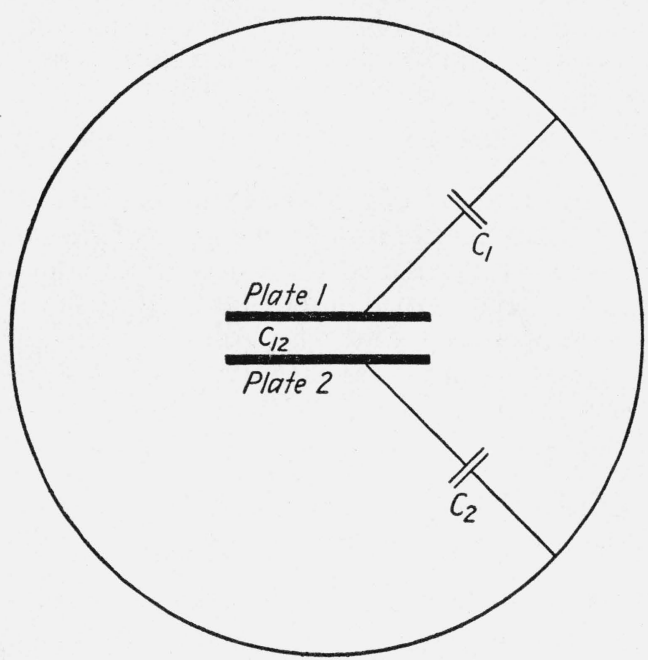
the system as two conducting plates situated near the center of a conducting sphere of infinite radius. If the plates are circular disks that are coaxial, and if the sphere is evacuated, all the coefficients of capacitance can be computed from the dimensions of the disks and the distance between them. If the plates are rectangles, no formula is available for computing the capacitance to earth.

The arrangement of electrodes inside of a sphere is shown diagrammatically in figure 2. The mutual capac-

FIGURE 2.-Diagram illustrating the coefficient of itance between plates 1 and capacitance of two parallel plates surrounded 2 is designated as $C_{12}$,
by an infinite sphere. whereas the capacitances between the plates and the

infinite sphere are designated as $C_{1}$ and $C_{2}$. It is convenient to consider $C_{12}$ as made up of two parts, $C_{n}$ and $C_{e}$. The normal capacitance, $C_{n}$, is the value that $C_{12}$ would have if the electricity were uniformly distributed over the inner surfaces of the electrodes, and if the lines of electrostatic intensity were all straight lines extending directly from one electrode to the other. The edge capacitance, $C_{e}$, is the correction that must be added to $C_{n}$ to give $C_{12}$. Values of $C_{n}$ and $C_{e}$ can be computed for circular electrodes and $C_{n}$ and $\left(C_{e}+C_{1}\right)$ for rectangular electrodes. In practical measurements one electrode (plate 2) is usually at earth potential, so that $C_{2}$ becomes zero and $C_{1}$ becomes the earth capacitance, $C_{g}$.

\section{EDGE CORRECTION FOR CIRCULAR ELECTRODES}

The formulas for computing the capacitances for $C_{n}$ and $C_{e}$ for circular electrodes ${ }^{2}$ of the same size are

$$
\begin{aligned}
& C_{n}={\frac{1.113 D^{2}}{16 b} \mu \mu \mathrm{f}}^{2} \\
& C_{z}=\frac{1.113 D}{8 \pi}\left[\ln \frac{8 \pi D}{b}-3+z\right] \mu \mu \mathrm{f},
\end{aligned}
$$

? G. Kirchhoff, On the Theory of Condensers, Monatsber. Akad. Wiss. Berlin (March 1877), p. 144; also Collected Works, p. 101 (Barth, Leipzig, 1882). A more recent paper is by J. W. Nicholson, Phil. Trans. 224A, 303 (1924), but his formula contains unsolved integrals. 
where

$D=$ diameter of each electrode in centimeters,

$b=$ distance between the inner faces of the electrodes in centimeters,

$t=$ thickness of each electrode in centimeters, and

$z=f(x)=(1+x) \ln (1+x)-x \ln x$

$x=t / b$, and

ln=a natural logarithm (2.303 times the common logarithm). Values of $z$ for any given value of $x$ can be obtained from the curve of figure 3 .

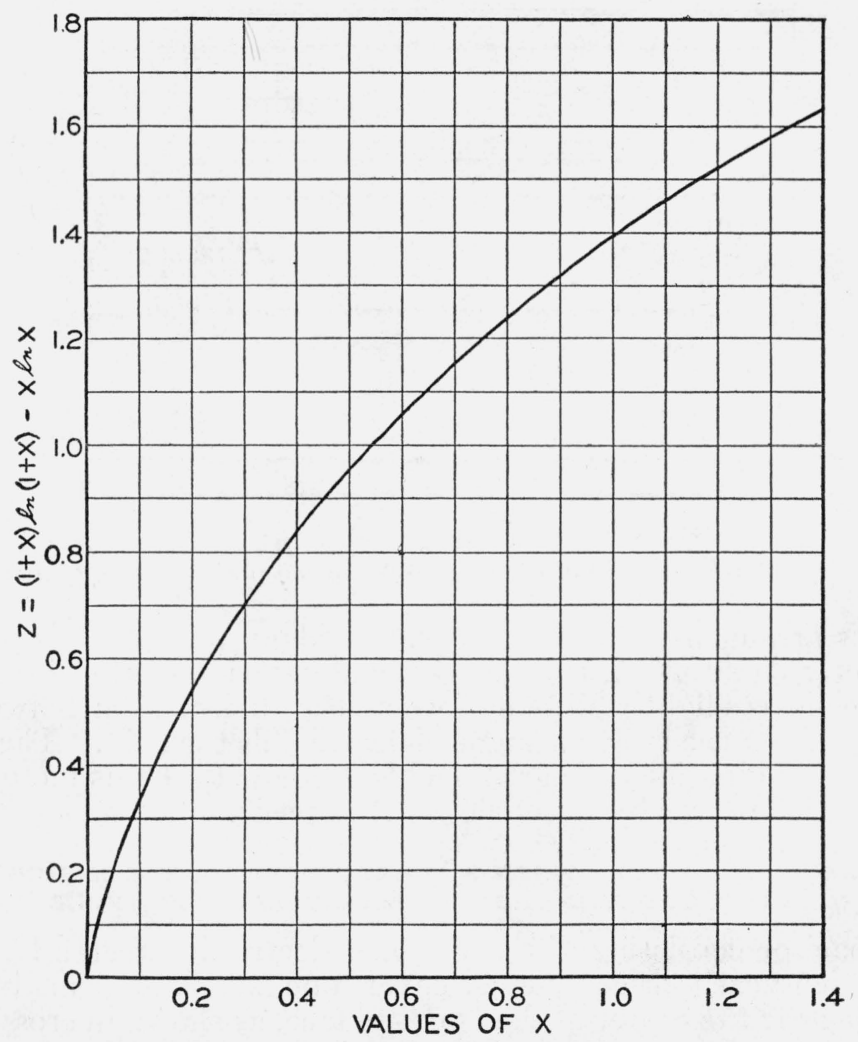

Figure 3.-Values of a function used in computing the edge capacitance.

Equation 3 was tested experimentally, as described in part 2, and was found to be correct within experimental error. This equation was used with four arrangements of electrodes.

(a) THEORETICAL FORMULA WHEN A CIRCULAR SHEET OF DIELECTRIC HAS ELECTRODES OF THE SAME DIAMETER AS THE SHEET

A capacitor consisting of a circular sheet of dielectric with electrodes completely covering both surfaces, as shown in cross section in figure $4(a)$, has a capacitance, $\boldsymbol{C}$, when measured, ${ }^{3}$ as previously described,

\footnotetext{
${ }^{3}$ Bold-faced symbols will be used to indicate measured capacitance.
} 
with one electrode at earth potential, which is related to the computed capacitance by the equation

$$
\boldsymbol{C}=K C_{n}+C_{e} \text {, approximately. }
$$

Hence

$$
K=\frac{\boldsymbol{C}-C_{e}}{C_{n}} \text {, approximately, }
$$

where $C_{n}$ and $C_{e}$ are obtained from eq 2 and 3 , respectively.

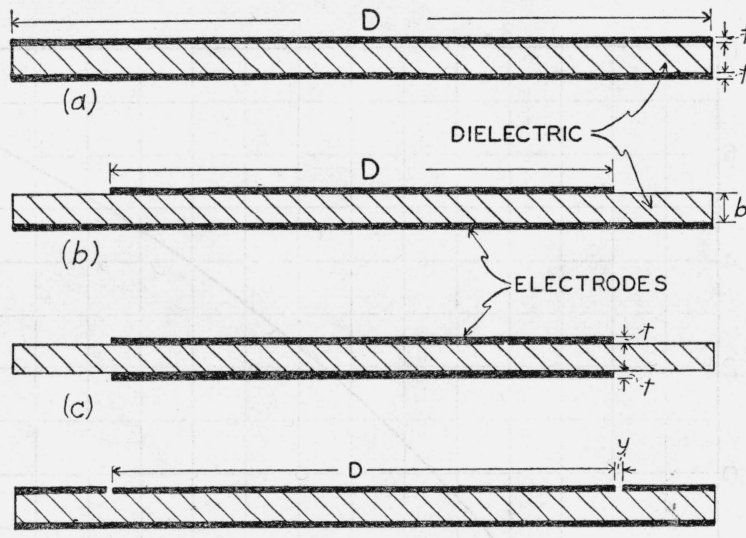

(d)

Figure 4.-Arrangement of circular electrodes on a single sheet of dielectric.

In this arrangement of electrodes, the edge capacitance is probably not exactly equal to $C_{e}$, because the configuration of the electric field at the edge is slightly different when the dielectric is between the electrodes from that when a single dielectric fills the field. The experimental determinations of part 2 (table 2) show that this method may yield values in error by as much as 1.1 percent.

(b) THEORETICAL FORMULA WHEN A SHEET OF DIELECTRIC HAS ONE LARGE ELECTRODE AND ONE SMALL CIRCULAR ELECTRODE

A capacitor consisting of a sheet of dielectric between a large electrode which nearly or completely covers one face, and a small circular electrode near the center of the opposite face, as shown in cross section in figure $4(b)$, has a capacitance, $\boldsymbol{C}$, when measured in the manner already described with the large electrode at earth potential, which is related to the computed capacitances by the equation

$$
C=K\left(C_{n}+C_{e}^{\prime}\right) \text {, approximately. }
$$

In deriving this equation, it was assumed that the large electrode was of infinite extent. In practice it was found sufficient if the large electrode extended beyond the small one by a distance equal to three times the thickness of the dielectric. From eq 7

$$
K=\frac{C}{C_{n}+C_{e}^{\prime}}, \text { approximately, }
$$


where $C_{n}$ is obtained from eq 2 , and $C_{e}^{\prime}$ is twice the value of the edge capacitance in air of an equal electrode capacitor in which the electrodes have the same diameter as the smaller electrode, and the distance between the electrodes is twice the thickness of the dielectric in the actual capacitor or

where

$$
C_{o}^{\prime}=1.113 \frac{D}{4 \pi}\left[\ln \frac{4 \pi D}{b}-3+z^{\prime}\right] \mu \mu f,
$$

$D=$ diameter of the smaller electrode in centimeters,

$b=$ thickness of the dielectric in centimeters, and

$z^{\prime}=f\left(x^{\prime}\right)$, (see eq 4 or fig. 3 )

$x^{\prime}=t / 2 b$,

$t=$ thickness of smaller electrode in centimeters.

In the above arrangement of electrodes, $K C_{e}^{\prime}$ is too large, because some of the lines of electric intensity at the edge pass partly through air. Hence, the value of $K$ obtained by this method will be smaller than the true value. The experimental results of part 2 (table 2) show that this method may be in error by as much as 6 percent.

This method can be made to give more accurate values if thin electrodes are used, by placing on the outside of the small electrode a sheet of dielectric of the same material as is between the electrodes. Although no experimental measurements have been made to prove it, the error of this method can, in this way, probably be made less than 1 percent.

(c) THEORETICAL FORMULA WHEN A SHEET OF DIELECTRIC EXTENDS BEYOND THE CIRCUMFERENCES OF THE ELECTRODES

A capacitor which consists of a relatively large sheet of dielectric between two equal circular electrodes that have their centers directly opposite each other, as shown in cross section in figure $4(c)$, has a measured capacitance, $\boldsymbol{C}$, which is related to the computed capacitances by the equation

Hence

$$
\boldsymbol{C}=K\left(C_{n}+C_{\ell}\right), \text { approximately. }
$$

$$
K=\frac{C}{C_{n}+C_{e}} \text {, approximately, }
$$

where $C_{n}$ and $C_{e}$ are obtained from eq 2 and 3 , respectively.

This method gives a value of $K$ that is too small, because the electric field beyond the edges of the electrodes was not all in the solid dielectric. The experimental determinations of part 2 (table 2) show that this method may be in error by as much as 7 percent.

It is possible to make this method more accurate by placing the dielectric material in more of the electric field. If thin electrodes such as tinfoil electrodes, are used, this can be done by placing sheets of the dielectric material on the outside of the electrodes as well as between them. The experimental results of part 2 (table 1) show that if sheets of the same dielectric material are placed on the outside of the electrodes as is between them, this method will give results in error by less than 1 percent. 
(d) ELIMINATION OF THE EDGE CORRECTION FOR CIRCULAR ELECTRODES BY USING A GUARD ELECTRODE

When a capacitor consists of a sheet of dielectric between a large electrode and a small circular electrode with a guard electrode surrounding it, as shown in cross section in figure $4(d)$, the edge correction is eliminated except for a slight effect due to the finite width of the gap between the small electrode and the guard electrode. The measured capacitance, $\boldsymbol{C}$, between the small or guarded electrode and the large electrode is related to the computed capacitance by the equation

\section{Hence}

$$
\boldsymbol{C}=K C_{n}{ }^{\prime} .
$$

$$
K=\mathrm{C} / C_{n}{ }^{\prime} .
$$

The value of $C_{n}{ }^{\prime}$ is obtained from eq 2 when $D$ is replaced by $D+y$, where $D$ is the diameter of the guarded electrode in centimeters and $y$ is the width of the gap between the guarded electrode and the guard electrode.

The addition of the width of the gap to the diameter of the guarded electrode serves as an approximate correction to take care of the error due to the finite width of the gap. This is equivalent to assuming that the guarded electrode extends to the center of the gap. In the extreme case where the width of the gap is equal to the thickness of the specimen and the thickness of the specimen is one-tenth the diameter of the guarded electrode, the error introduced by this approximation is less than 1 percent. The dimensions used in the experimental part of this paper were such that errors less than 0.1 percent were introduced. The width of the guard ring should be at least twice the thickness of the specimen.

This is the most accurate of the methods discussed in this paper. The dielectric fills the entire field between the electrodes, and this field is uniform except for the slight variation at the edge of the guarded electrode due to the finite width of the gap. If the gap is made small, the correction given above is sufficiently accurate, so that the error by this method is negligible.

It should be observed that the measuring circuit must be such that only the capacitance between the guarded electrode and the opposite electrode is measured.

\section{EDGE CORRECTION FOR RECTANGULAR ELECTRODES}

The normal capacitance, $C_{n}$, and the sum of the edge capacitance, $C_{e}$, and the earth capacitance, $C_{g}$, when the electrodes are rectangular plates which form the opposite faces of a rectangular parallelopiped, and when they are in an evacuated infinite sphere, are given by the following formulas:

$$
\begin{gathered}
C_{n}=\frac{1.113 \ln w}{4 \pi b} \mu \mu f, \\
C_{e}+C_{o}=1.113 \frac{l}{4 \pi^{2}}\left\{1+\ln \left[1+\frac{\pi w}{b}+\ln \left(1+\frac{\pi w}{b}\right)\right]\right\} \\
+\frac{1.113 w}{4 \pi^{2}}\left\{1+\ln \left[1+\frac{\pi l}{b}+\ln \left(1+\frac{\pi l}{b}\right)\right]\right\} \mu \mu f,
\end{gathered}
$$


where

$b=$ thickness of the dielectric in centimeters,

$w=$ width of the electrodes in centimeters, and

$l=$ length of the electrode in centimeters.

No formula is available for separating $C_{e}$ and $C_{g}$ as was the case for circular electrodes. One of the limits to the accuracy of this equation is the uncertainty of the value of $C_{0}$.

The formulas were deduced from the equation given by Thomson ${ }^{4}$ for the distribution of electricity along the edges of two semi-infinite, parallel electrodes which have their edges in a plane perpendicular to the electrodes. Coursey ${ }^{5}$ gives a formula for the capacitance of rectangular plates which is the sum of eq 14 and 15, except that the correction at the ends was neglected. Equation 15 assumes that the electrodes are so wide that the effect of one edge does not extend as far as the opposite edge. Furthermore, the derivation does not consider the thickness of the electrodes. Hence, eq 15 should be used only when the electrodes are thin and wide relative to the thickness of the dielectric. Even with these restrictions, the formula for $C_{e}$ is less accurate than the similar formula with circular electrodes, especially since $C_{g}$ is included. Four different arrangements of electrodes for single sheets of material will be considered that are analogous to the four cases for circular electrodes.

(a) THEORETICAL FORMULA WHEN A RECTANGULAR SHEET OF DIELECTRIC HAS ELECTRODES COVERING BOTH FACES

A rectangular sheet of dielectric with electrodes that cover both faces is analogous to the case of circular electrodes that cover both faces of the dielectric. Hence

$$
K=\frac{C-C_{e}}{C_{n}} \text {, approximately, }
$$

where the values of $C_{n}$ and $C_{e}$ must be computed by eq 14 and 15 .

The dielectric constant, when determined by this method, is less accurate than when circular electrodes are employed, since the experimental results of part 2 (table 3 ) show that this method may give values in error by as much as 2.3 percent.

(b) THEORETICAL FORMULA WHEN A SHEET OF DIELECTRIC HAS ONE LARGE ELECTRODE AND ONE SMALL RECTANGULAR ELECTRODE

A sheet of dielectric with a small rectangular electrode on one face and a larger electrode on the opposite face, so placed that it extends beyond the edges of the smaller electrode, is analogous to the case of a large electrode with a small circular electrode opposite it. Hence

$$
K=\frac{C}{C_{n}+C_{e}^{\prime}}
$$

The value of $C_{n}$ is given by eq 14 , and the value of $C_{e}^{\prime}$ can be obtained from $C_{e}$ (eq 15) in the same manner as was done for the analogous

${ }^{4}$ J. J. Thomson, Recent Researches in Electricity and Magnetism, p. 216 (Clarendon Press, Oxford, England, 1893).

5 P. R. Coursey, Electrical Condensers, p. 138 (Sir Isaac Pitman and Sons, Ltd., London, 1927). 
case with circular electrodes. The value of $C_{e}^{\prime}$ (assuming $C_{g}$ to be negligible) is given by

$$
\begin{aligned}
& C_{e}^{\prime}=\frac{1.113 l}{2 \pi^{2}}\left\{1+\ln \left[1+\frac{\pi w}{2 b}+\ln \left(1+\frac{\pi w}{2 b}\right)\right]\right\} \\
& +\frac{1.113 w}{2 \pi^{2}}\left\{1+\ln \left[1+\frac{\pi l}{2 b}+\ln \left(1+\frac{\pi l}{2 b}\right)\right]\right\} \mu \mu f .
\end{aligned}
$$

This method will give values which are too small, because the electric field beyond the edge of the smaller electrode is not all in the solid dielectric. The experimental data of part 2 (table 3) show that the error may be as much as 14 percent.

(c) THEORETICAL FORMULA WHEN A SHEET OF DIELECTRIC EXTENDS BEXOND THE EDGES OF RECTANGULAR ELECTRODES

A sheet of dielectric which extends beyond the edges of equal rectangular electrodes that are opposite each other is analogous to the case of small circular electrodes. Hence

$$
K=\frac{C}{C_{n}+C_{e}}, \text { approximately, }
$$

where the values of $C_{n}$ and $C_{e}$ are obtained from eq 14 and 15 , respectively.

The result is less accurate than for the similar case using circular electrodes. This arrangement may give results that are as much as 10 percent too small, as indicated by the experimental determinations of part 2 (table 3 ).

(d) ELIMINATION OF THE EDGE CORRECTION FOR RECTANGULAR ELECTRODES BY USING A GUARD ELECTRODE

When a capacitor consists of a sheet of dielectric between a large electrode and a small rectangular electrode surrounded by a guard electrode, the edge correction is eliminated except for a slight effect due to the finite width of the gap between the guarded electrode and the guard electrode. This is analogous to the guarded electrode case of circular electrodes. Hence

$$
K=\frac{C}{C_{n}^{\prime}} \text {. }
$$

The value of $C_{n}^{\prime}$ is obtained from eq 14 by replacing $l$ by $(l+y)$ and $w$ by $(w+y)$, where $y$ is the width in centimeters of the gap between the guarded electrode and the guard electrode, and $l$ and $w$ are the length and width, respectively, of the guarded electrode.

As in the case of circular electrodes, the dielectric fills the entire field, and this field is uniform except for the slight variation at the edge of the guarded electrode due to the finite width of the gap. Considerations as to the width of the gap and the width of the guard electrode are similar to those for circular electrodes.

\section{THEORY OF EDGE CORRECTION WITH TWO SHEETS OF DIELECTRIC}

When two similar sheets of dielectric have one common electrode between them, and the two outside electrodes are connected together, the edge correction of this capacitor cannot be computed by the formula given for a single sheet of dielectric. Moreover, the same 
symmetry does not exist between the different cases as when only a single sheet of dielectric is employed. However, the capacitance to earth does not enter into the problem in any case.

\section{EDGE CORRECTION FOR CIRCULAR ELECTRODES}

The normal capacitance, $C_{n}$, must be computed for each sheet by the formula given in a preceding section, and the total normal capacitance taken as the sum of the values for the two sheets. The formulas for the edge capacitance do not have as satisfactory theoretical basis

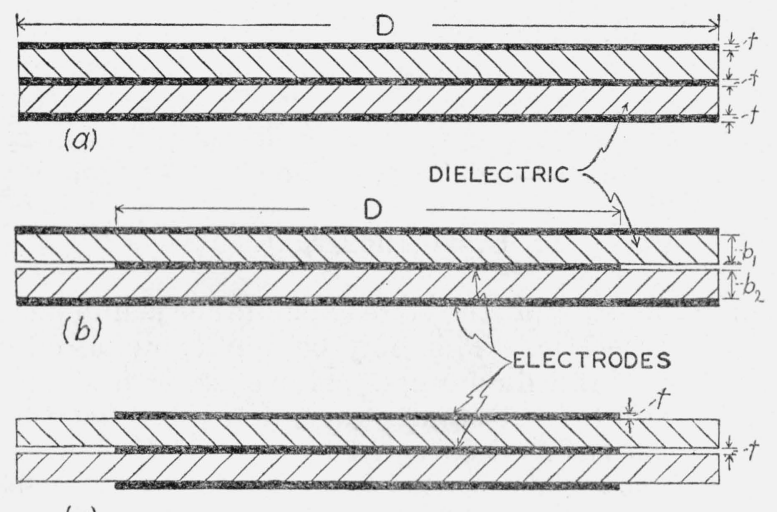

(c)

FIGURE 5.-Arrangement of circular electrodes when two sheets"of dielectric are used.

as the similar formulas for a single sheet. However, experimental determinations with circular electrodes on two sheets give values of the dielectric constant which agree well with accepted values when the center electrode is smaller than the other two.

Formulas are available for three different arrangements of circular electrodes. A diagram, showing a cross section through the center, is given in figure 5 for each of these arrangements.

(a) THEORETICAL FORMULA WHEN THE TWO SHEETS OF DIELECTRIC AND THE ELECTRODES HAVE THE SAME DIAMETER

When two circular sheets of a dielectric material, both having the same diameter, are assembled with three circular electrodes having the same diameter as the sheets of dielectric, as shown in cross section in figure $5(a)$, the measured capacitance, $C$, between the center electrode and the two outside ones is related to the computed capacitances by the equation

so that

$$
\boldsymbol{C}=K\left(C_{n 1}+C_{n 2}\right)+C_{e}, \text { approximately, }
$$

w here

$$
K=\frac{C-C_{e}}{C_{n 1}+C_{n 2}}, \text { approximately, }
$$

$$
\begin{gathered}
C_{n 1}=1.113 \frac{D^{2}}{16 b_{1}} \mu \mu f, \\
C_{n 2}=1.113 \frac{D^{2}}{16 b_{2}} \mu \mu f, \\
C_{e}=\frac{1.113 D}{\pi}\left[0.5539+\frac{1}{6}\left(z_{2}+z_{3}\right)\right] \mu \mu f,
\end{gathered}
$$


where

$z_{2}=f\left(x_{2}\right)$ (see eq 4 or fig. 3 ),

$z_{3}=f\left(x_{3}\right)$ (see eq 4 or fig. 3 ),

$x_{2}=2 t / b_{1}$,

$x_{3}=2 t / b_{2}$,

$D=$ diameter of the electrode in centimeters,

$b_{1}=$ thickness of one sheet in centimeters,

$b_{2}=$ thickness of the second sheet in centimeters, and

$t=$ thickness of each conducting disk in centimeters.

The formula for $C_{e}$ was derived by Grüneisen and Giebe, ${ }^{6}$ who have published only the final formula and state that the derivation has not been rigorously carried through.

If the electrodes are thin, as for tinfoil electrodes, both $z_{2}$ and $z_{3}$ are so small that they can be neglected. Then eq 25 becomes

$$
C_{e}=0.1962 D \mu \mu f
$$

This equation indicates that the edge capacitance is independent of the thickness of the dielectric. This may be applicable only for a limited range of thicknesses and diameters. However, Grüneisen and Giebe measured and computed the capacitance of 13 air capacitors, in which the diameter of the electrodes varied from 15 to $30 \mathrm{~cm}$, the distance between adjacent electrodes varied from 1 to $3 \mathrm{~cm}$, and the thickness of the electrodes varied from 0.08 to $0.59 \mathrm{~cm}$. The difference between the computed and observed capacitance was, in 1 case, 2 percent of the measured capacitance, but in all the other 12 cases it was less than 1 percent. It appears that the difference was not greater than the error of measurement. Hence, the formula may be considered satisfactory. However, in this arrangement of electrodes with dielectric material between them, the edge capacitance is not exactly equal to $C_{e}$ because the configuration of the electric field at the edge is slightly different when the dielectric is between the electrodes from that when air is the only dielectric. This error may amount to 1 percent as shown by the experimental data in part 2 (table 2 ).

(B) THEORETICAL FORMULA WHEN THE OUTER ELECTRODES AND THE TWO SHEETS OF DIELECTRIC EXTEND BEYOND THE CIRCUMFERENCE OF THE CENTER ELECTRODE

When two large sheets of a dielectric are assembled with three electrodes, the center one being circular and smaller than the other electrodes and the sheets, as shown in cross section in figure 5 (b), the measured capacitance $\boldsymbol{C}$ between the center electrode and the two outside ones is related to the computed capacitances by the equation

so that

$$
\boldsymbol{C}=K\left(C_{n 1}+C_{n 2}+C_{e}^{\prime}\right) \text { approximately, }
$$

$$
K=\frac{C}{C_{n 1}+C_{n 2}+C_{e}^{\prime}} \quad \text { approximately, }
$$

where $C_{n 1}$ and $C_{n 2}$ are the same as in the two preceding sections, and

$$
C_{e}^{\prime}=\frac{1.113 D}{\pi}\left[0.6932+z_{4}+z_{5}\right] \mu \mu f,
$$

\footnotetext{
${ }^{6} \mathrm{E}$. Grüneisen and $\mathrm{E}$. Giebe, Use of the three-plate capacitor for the determination of the dielectric constant of solid bodies, Verhandl. deut. physik. Ges. 14, 921 (1912).
} 
where

$z_{4}=f\left(x_{4}\right)$ (see eq 4 or fig. 3 )

$z_{5}=f\left(x_{5}\right)$ (see eq 4 or fig. 3 )

$x_{4}=t / 4 b_{1}$

$x_{5}=t / 4 b_{2}$

$D=$ diameter of the small interior electrode in centimeters,

$b_{1}=$ thickness of one sheet of dielectric in centimeters,

$b_{2}=$ thickness of the second sheet of dielectric in centimenters, and

$t=$ thickness of the inner electrode in centimeters.

The equation for $C_{e}^{\prime}$ which was derived by Thomson ${ }^{7}$ for the edge of a semi-infinite plate midway between two infinite plates was applied here without alteration to the circular electrodes. If the electrode is so thin, as in the case of tinfoil electrodes, that $z_{4}$ and $z_{5}$ are negligible,

$$
C_{e}^{\prime}=0.2456 D_{\mu \mu f}
$$

This equation has the same form as the one for $C_{e}$ given by Grüneisen and Giebe for three equal electrodes. However, the relation between the constants of the two equations is not evident. This method gives a value of $K$ that is more nearly correct than any of the other methods described. The experimental data of part 2 (table 2) show that this method will give errors less than 0.6 percent when thin electrodes such as tinfoil are used.

(C) THEORETICAL FORMULA WHEN THE TWO SHEETS OF DIELECTRIC EXTEND BEYOND THE CIRCUMFERENCES OF THE ELECTRODES

When two large sheets of a dielectric are assembled, as shown in cross section in figure $5(c)$, with three smaller circular electrodes all of the same diameter and with their centers in a line perpendicular to the faces of the electrodes, the measured capacitance, $\boldsymbol{C}$, between the center electrode and the two outside ones is related to the computed capacitance by the formula

$$
C=K\left(C_{n 1}+C_{n 2}+C_{e}\right) \text { approximately. }
$$

Hence

$$
K=\frac{C}{C_{n 1}+C_{n 2}+C_{e}} \text { approximately, }
$$

where the values of $C_{n 1}, C_{n 2}$, and $C_{e}$ are the same as given in the preceding section.

The value of $K$ obtained by this method is smaller than the true value, because the field beyond the edges of the electrodes is not all in the solid dielectric. The amount of this error may be as much as 4 percent, as shown by the experimental results given in part 2 (table 2).

\section{EDGE CORRECTION FOR RECTANGULAR ELECTRODES}

There is only one arrangement of rectangular electrodes on two sheets of dielectric for which a formula is available. This is analogous to the case just treated of a small circular electrode between two large sheets of dielectric which have large electrodes on their outer faces. ${ }^{7}$ J. J. Thomson, Recent Researches in Electricity and Magnetism, p. 211 (Clarendon Press, Oxford,
England, 1893). 
(a) THEORETICAL FORMULA WHEN THE OUTER ELECTRODES AND THE TWO SHEETS OF DIELECTRIC EXTEND BEYOND THE PERIMETER OF THE CENTER ELECTRODE

When two sheets of dielectric are assembled with three electrodes, so that both the dielectric sheets and outside electrodes extend some distance beyond the edges of the center electrode which is in the form of a rectangular plate, the dielectric constant is given by the equation

where

$$
K=\frac{C}{C_{n 1}+C_{n 2}+C_{e}^{\prime}}
$$

$$
\begin{aligned}
C_{n 1} & =\frac{1.113 l w}{4 \pi b_{1}} \mu \mu \mathrm{f}, \\
C_{n 2} & =\frac{1.113 l w}{4 \pi b_{2}} \mu \mu \mathrm{f}, \\
C_{e}^{\prime} & =\frac{1.113(2 l+2 w)}{\pi^{2}}\left[0.6932+z_{4}+z_{5}\right] \mu \mu \mathrm{f},
\end{aligned}
$$

where $z_{4}, z_{5}, b_{1}, b_{2}$, and $t$ are the same as the preceding section, which is the analogous case for circular electrodes, and where

$w=$ width of the center electrode in centimeters, and

$l=$ length of the center electrode in centimeters.

The equation for $C_{e}^{\prime}$ was obtained from the equation given by Thomson ${ }^{8}$ for the distribution of electricity on a semi-infinite plate with one straight edge when midway between two infinite plates. In extending this to the case here considered, the assumption is made that the center strip is so wide that the effect of one edge on the distribution of electricity does not extend to the opposite edge. If the electrodes are so thin that $z_{4}+z_{5}$ can be neglected, then

$$
C_{e}^{\prime}=0.07818(l+w) \mu \mu \mathrm{f} .
$$

This method will give results which are in error by less than 0.5 percent as shown by the experimental results in part 2 (table 3 ).

\section{PART 2. EXPERIMENTAL DETERMINATION OF THE EDGE CORRECTION}

\section{INTRODUCTION}

The assumptions used in the derivations of the theoretical equations given in part 1 for the computation of the dielectric constants of sheet materials were such that appreciable errors in the results might be expected. It was therefore desirable that these equations be experimentally tested to determine their accuracy. This has been done for arrangements where both circular and rectangular electrodes were used. The values of the dielectric constant which were obtained when a guard electrode was used, were taken to be correct, and the values obtained from other arrangements of the electrodes were compared with them.

It was also deemed desirable to test the accuracy of Kirchhoff's equation (eq 3), since it was the basis for the equations used in the

\footnotetext{
${ }^{8}$ J. J. Thomson, Recent Researches in Electricity and Magnetism, p. 211 (Clarendon Press, Oxford, England, 1893).
} 
methods where a single sheet of dielectric material was equipped with circular electrodes. This was done in two ways. One method was the construction of an air capacitor whose capacitance could be computed as well as measured. The other method was to surround the electrodes, as nearly as possible, by the dielectric. This was accomplished by using small electrodes on a large sheet of dielectric and then placing large sheets of dielectric outside the electrodes.

The specimens on which measurements were made had thicknesses which ranged from 0.07 to $0.70 \mathrm{~cm}$ and dielectric constants which ranged from 2.6 to 70.0 . The circular specimens were all $15 \mathrm{~cm}$ in diameter, except for three samples of titania which were $12 \mathrm{~cm}$ in diameter. The rectangular specimens had lengths ranging from 12 to $88 \mathrm{~cm}$ and widths from 8 to $12 \mathrm{~cm}$. These specimens are listed in the first columns of tables 2 and 3. All the specimens except the porcelain and titania were cut from uniform sheets of material. The titania, which was a mixture of titanium oxide in a porcelain base, was obtained in disk form. No particular care was taken in the selection of the materials except for the marble specimens, which were cut from slabs carefully selected as to uniformity of appearance. Only two of the materials were measured using rectangular electrodes, namely, methyl methacrylate and glass.

\section{ARRANGEMENT OF ELECTRODES}

Tinfoil was used as the electrode material. This was applied with a thin coat of petrolatum and carefully rolled down on the surface of the specimen with a narrow roller until no visible imprint could be made on the tinfoil with the roller. Experiments were made which showed that this procedure of rolling was necessary if the formation of bubbles under the electrodes was to be avoided. When the tinfoil was rubbed down in the usual manner, gas bubbles became visible under the tinfoil in less than 24 hours. However, when the tinfoil was rolled down with a narrow roller on which considerable pressure was exerted until no imprint could be made on the tinfoil, no bubbles appeared under the tinfoil within several months.

The electrodes were applied to the specimens only once and served for all the various arrangements. For each material two or more single specimens were used. The electrodes were cut and modified as needed for the different arrangements but were not removed and replaced. This was accomplished by first using the arrangements where the electrodes completely covered the faces of the specimens and removing parts of these electrodes as required for the other arrangements. To provide a guard ring, a strip of electrode $0.05 \mathrm{~cm}$ wide was removed from one electrode. The width of the guard ring was $2.0 \mathrm{~cm}$. The removal of the guard ring provided the arrangement having one electrode larger than the other. The arrangement consisting of electrodes of the same size but smaller than the dielectric was obtained by cutting the larger electrode to the size of the smaller one. The double specimens were obtained by facing together two single specimens.

The dielectric constants for these various electrode arrangements were computed by means of the corresponding equations given in part 1. The electrodes used on the solid dielectrics were tinfoil 
having a thickness of $0.003 \mathrm{~cm}$. The terms of the equations involving the thickness were so small for this thickness that neglecting them would not alter the result by 0.1 percent; therefore they were omitted from the equations when the dielectric constants were computed.

\section{ELECTRICAL MEASUREMENTS}

The capacitance measurements were made with a conjugate Schering bridge provided with an earthing arm. ${ }^{9}$ The bridge was well shielded and was operated inside an earthed cage. A balance of the bridge was first obtained without the specimen being connected to it. Then the specimen was connected in parallel with the standard capacitor and the bridge rebalanced. The capacitance of the specimen was taken as equal to the change in capacitance of the standard capacitor necessary to again bring the bridge into balance. The
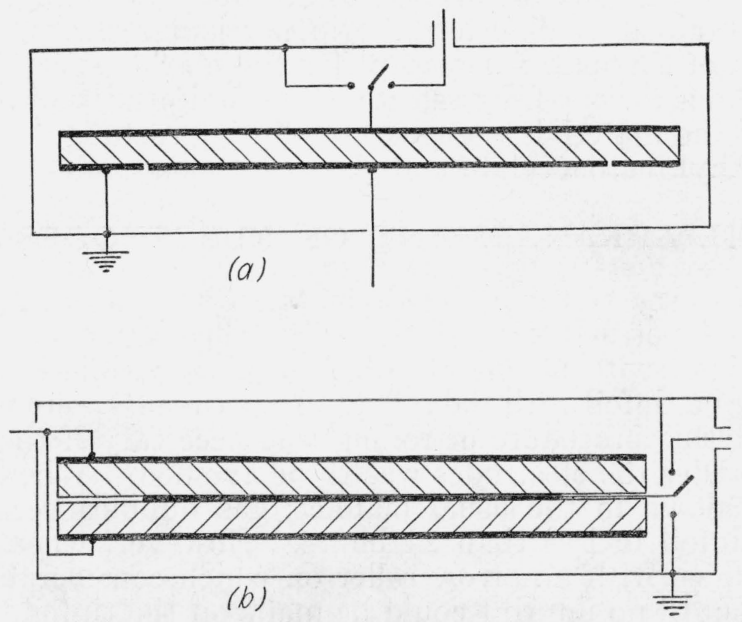

FIGURE 6.-Shielding arrangements.

(a) For a single specimen (guard ring may be removed). (b) For a double specimen. These figures are not drawn to scale. The shield should be at least $8 \mathrm{~cm}$ from the specimen if serious distortion of the field is to be avoided.

source of $1,000 \mathrm{c} / \mathrm{s}$ measuring current for part of the work was a motor-generator energized by storage batteries. For the remainder of the work an amplified 1,000-cycle signal from a crystal clock was filtered and used as a source. In either case a potential of 110 volts was applied across the bridge, which put 55 volts across the specimen.

The specimens were placed in a metal box which served as a shield for the specimens and was part of a constant-temperature chamber. When measured singly, the specimens were mounted as shown diagrammatically in figure $6(a)$. (The guard and its connection can be removed.) The switch used for disconnecting the high potential lead of the specimen from the bridge and connecting it to earth was mounted in the box. This served effectively to shield the switch. When the double specimens were measured, they were mounted as

$\checkmark$ This bridge is described in a tentative method of the ASTM entitled, Tentative methods of testing electrical insulating material for power factor and dielectric constant, D150-36T. See Proc. Am. Soc. Testing Materials 36, 955 (1936). A bridge of the same form but with more elaborate shielding than was here used is described by A. V. Astin, Measurements of relative and true power factors of air capacitors, J. Research NBS 21, 425 (1938) RP1138. 
shown diagrammatically in figure $6(b)$. Here it was necessary to mount the switch in a separate compartment. It was found that the shield should be at least $8 \mathrm{~cm}$ from any part of the specimen. Closer proximity of the shield to the specimen affected the edge capacitance. The shielding in both cases was designed to eliminate as far as possible direct capacitance between the leads and between each lead and the opposite electrode. This effectively removed from the measurement any capacitance other than the capacitance between the electrodes in all cases except one. When the double specimens were measured and the center electrode was smaller than the outer electrode, it was necessary to make connection to the center electrode with a small wire. This wire could not be shielded along the distance from the edge of the specimens to the center electrode, and the capacitance of this lead to the outer electrode was included in the measured capacitance. This lead capacitance was determined by using a dummy lead as nearly like the real lead as possible and symmetrically placed with respect to it. Assuming that the capacitance of the real lead was the same as that of the dummy, the measured capacitance of the specimen could be corrected for the lead capacitance.

The specimens were maintained at $30^{\circ} \mathrm{C}$ in a dry atmosphere for at least 48 hours before measurements were made. The capacitance was measured without removing the specimens from the chamber. The marble specimens were dried by placing them in an oven at $115^{\circ} \mathrm{C}$ for 24 hours before being placed in a measuring chamber.

\section{RESULTS}

Measurements were made on both circular and rectangular specimens to determine the accuracy of the theoretical equations which have been given in part 1. The results have also been used to set up empirical equations which give more accurate values of the dielectric constants than the theoretical equations.

Specimens with circular electrodes have been used, not only to measure dielectric constants but also to test the validity of Kirchhoff's formula for edge correction. For the latter purpose, one of the dielectrics used was air.

\section{TEST OF KIRCHHOFF'S EQUATION}

The validity of Kirchhoff's equation for the capacitance between coaxial circular electrodes when completely surrounded by a uniform dielectric was tested by using both air and methyl methacrylate as the dielectric. When air was used as the dielectric, the field between the electrodes was completely filled with a uniform dielectric as postulated in the theoretical derivation of the equation except for the small volume occupied by the spacers. The electrodes were monel metal disks $20.01 \mathrm{~cm}$ in diameter and $0.451 \mathrm{~cm}$ thick, whose surfaces were ground flat to within $0.0008 \mathrm{~cm}$. The disks were spaced by three quartz cylinders all of the same length within $2 \mu$ and all having a diameter of about $0.3 \mathrm{~cm}$. Three different sets were used having lengths of $0.1874 \mathrm{~cm}, 0.4027 \mathrm{~cm}$, and $0.5900 \mathrm{~cm}$.

When methyl methacrylate was used as the dielectric, the electrodes were sheets of tinfoil about $30 \mu$ thick. In order that the field 
should be as nearly as possible all in the solid dielectric, a sheet of the same dielectric $1 \frac{1 / 4}{\mathrm{~cm}}$ thick and larger than the specimen was placed on each side of the specimen. A hole in each of the outside pieces of dielectric allowed electrical connection to the tinfoil electrodes.

The results of the measurements are given in table 1 . The capacitances as measured by the methods described above are given in the fourth column, and the capacitances, as computed by Kirchhoff's equation are given in the fifth column. The percentage differences between the computed and measured values are given in the last column. The differences are all less than 1 percent, which is within experimental error. Hence there is no indication of an error in Kirchhoff's equation.

TABLE 1.-Test of Kirchhoff's equation for the capacitance between two coaxial circular electrodes of the same diameter

[Kirchhoff's equation is $\boldsymbol{C}=K\left(\boldsymbol{C}_{n}+\boldsymbol{C}_{\mathrm{e}}\right)$, where $\boldsymbol{C}_{n}$ and $\boldsymbol{C}_{\boldsymbol{6}}$ are given by eq 2 and 3, p. 750]

\begin{tabular}{|c|c|c|c|c|c|c|c|}
\hline Dielectric & $\begin{array}{l}\text { Electrode } \\
\text { thickness }\end{array}$ & $\begin{array}{l}\text { Electrode } \\
\text { diameter }\end{array}$ & Spacing & $\begin{array}{l}\text { Dielectric } \\
\text { constant of } \\
\text { surround- } \\
\text { ing ma- } \\
\text { terial }^{1}\end{array}$ & $\begin{array}{c}\text { Measured } \\
\text { capaci- } \\
\text { tance }\end{array}$ & $\begin{array}{c}\text { Com- } \\
\text { puted } \\
\text { capaci- } \\
\text { tance }\end{array}$ & $\begin{array}{l}\text { Differ- } \\
\text { ence }\end{array}$ \\
\hline $\begin{array}{l}\text { Air } \\
\text { Do } \\
\text { Do } \\
\text { Methyl methacrylate } \\
\text { Do } \\
\text { Do } \\
\text { Do }\end{array}$ & $\begin{array}{l}c m \\
0.451 \\
.451 \\
.451 \\
.003 \\
.003 \\
.003 \\
.003\end{array}$ & $\begin{array}{l}c m \\
20.01 \\
20.01 \\
20.01 \\
11.00 \\
10.99 \\
10.98 \\
11.01\end{array}$ & $\begin{array}{l}c m \\
0.1874 \\
.4027 \\
.5900 \\
.0887 \\
.2591 \\
.4680 \\
.7020\end{array}$ & $\begin{array}{l}\text { 1. } 000 \\
\text { 1. } 000 \\
\text { 1. } 000 \\
\text { 3. } 315 \\
\text { 3. } 292 \\
\text { 3. } 310 \\
\text { 3. } 309\end{array}$ & \begin{tabular}{r}
\multicolumn{1}{c}{$\mu \mu f$} \\
155.1 \\
74.0 \\
51.4 \\
323.4 \\
113.4 \\
65.2 \\
44.8
\end{tabular} & $\begin{array}{r}\mu \mu f \\
154.7 \\
74.0 \\
51.6 \\
322.8 \\
113.1 \\
64.7 \\
44.5\end{array}$ & $\begin{array}{l}\% \\
-0.3 \\
.0 \\
+.4 \\
-.2 \\
-.3 \\
-.8 \\
-.8\end{array}$ \\
\hline
\end{tabular}

1 Dielectric constant of air was taken from tables; that of methyl methacrylate was measured by a guardring capacitor.

\section{DIELECTRIC CONSTANTS WHEN THEORETICAL EQUATIONS} WERE USED

\section{(a) CIRCULAR ELECTRODES}

The percentage errors in a large number of determinations of the dielectric constant for the various arrangements of circular electrodes, using the equations derived in part 1 of this paper, are given in table 2. These errors were computed on the assumption that the dielectric constant as determined by a guard-ring capacitor was correct. The negative sign indicates that the value of the dielectric constant obtained by the theoretical equation is smaller than the correct value.

Each value given in table 2, in most cases, is the average of several determinations. The number of specimens given in the second column is the number of determinations for those electrode arrangements which require a single specimen, namely, arrangements $4 \mathrm{a}, 4 \mathrm{~b}$, and $4 \mathrm{c}$. The number of determinations for the electrode arrangements where two specimens were required is only half the number of specimens. The average values of thickness and dielectric constant are given in the third and fourth columns in order to show the ranges of thickness and dielectric constant which were covered.

The electrode arrangement giving the least error was $5 \mathrm{~b}$, which is for a pair of specimens having the center electrode smaller than the other two. It was computed by means of eq 28. The values obtained by this method are correct within experimental error. 


\begin{tabular}{|c|c|c|c|c|c|c|c|c|c|}
\hline \multicolumn{4}{|c|}{ 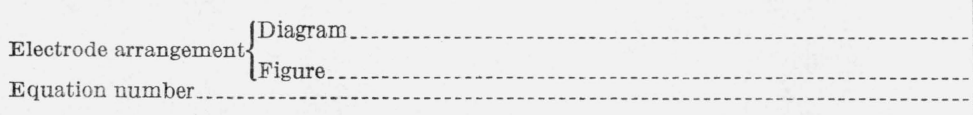 } & $\begin{array}{l}4(a) \\
6\end{array}$ & $\begin{array}{l}5(a) \\
22\end{array}$ & $\begin{array}{l}4(b) \\
8\end{array}$ & $\begin{array}{c}5(b) \\
28\end{array}$ & $\begin{array}{l}4(c) \\
11\end{array}$ & $\begin{array}{l}\text { लिखिए } \\
5(c) \\
32\end{array}$ \\
\hline Material & $\begin{array}{l}\text { Number of } \\
\text { specimens }\end{array}$ & $\begin{array}{l}\text { Thickness } \\
\text { in } \mathrm{cm}\end{array}$ & $\begin{array}{l}\text { Dielectric } \\
\text { constant }\end{array}$ & \multicolumn{6}{|c|}{ Percentage error } \\
\hline 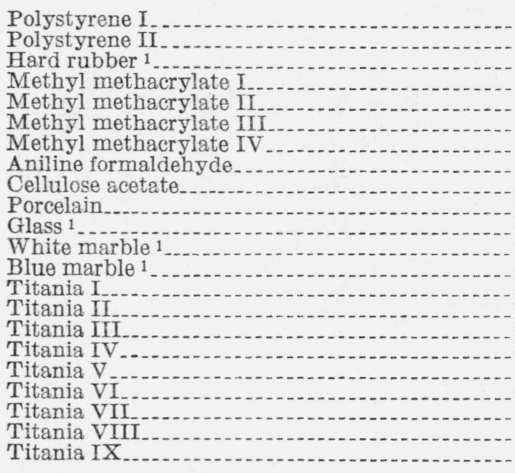 & $\begin{array}{l}2 \\
2 \\
8 \\
8 \\
4 \\
8 \\
8 \\
1 \\
4 \\
1 \\
8 \\
6 \\
4 \\
2 \\
2 \\
2 \\
1 \\
2 \\
2 \\
3 \\
2 \\
2\end{array}$ & $\begin{array}{l}0.653 \\
.474 \\
.471 \\
.697 \\
.467 \\
.258 \\
.081 \\
.302 \\
.312 \\
.597 \\
.467 \\
.754 \\
.703 \\
.608 \\
.256 \\
.625 \\
.589 \\
.554 \\
.249 \\
.609 \\
.274 \\
.142\end{array}$ & $\begin{array}{l}2.58 \\
2.57 \\
3.12 \\
3.29 \\
3.31 \\
3.28 \\
3.32 \\
3.71 \\
5.14 \\
6.19 \\
7.76 \\
8.60 \\
8.75 \\
14.2 \\
15.7 \\
54.0 \\
57.4 \\
57.0 \\
57.1 \\
70.5 \\
68.5 \\
70.6\end{array}$ & $\begin{array}{r}-0.6 \\
-1.1 \\
-0.8 \\
-.8 \\
-.5 \\
-.2 \\
+.6 \\
+.1 \\
+.1\end{array}$ & $\begin{array}{r}-0.7 \\
-1.1 \\
-0.9 \\
-.9 \\
-.4 \\
-.2 \\
+.5 \\
-.2 \\
-.2\end{array}$ & $\begin{array}{l}-0.6 \\
-1.5 \\
-1.8 \\
-1.6 \\
-2.1 \\
-2.4 \\
-1.4 \\
-2.5 \\
-3.5 \\
-3.2 \\
-4.4 \\
-3.8 \\
-3.9 \\
-3.4 \\
-4.5 \\
-5.5 \\
-5.7 \\
-6.0 \\
-5.0 \\
-5.0 \\
-5.4 \\
-4.1\end{array}$ & $\begin{array}{r}-0.5 \\
-.2 \\
.0 \\
+.4 \\
+.3 \\
+.2 \\
+.1 \\
+.3 \\
+.6\end{array}$ & $\begin{array}{l}-4.1 \\
-3.4 \\
-3.0 \\
-4.4 \\
-3.6 \\
-2.6 \\
-1.0 \\
-2.9 \\
-3.3 \\
-4.4 \\
-4.5 \\
-5.7 \\
-5.5 \\
-5.2 \\
-3.5 \\
-5.6 \\
-5.6 \\
-5.4 \\
-3.7 \\
-7.2 \\
-4.0 \\
-2.6\end{array}$ & $\begin{array}{l}-3.1 \\
-4.3 \\
-2.3 \\
-1.3 \\
-0.2 \\
-1.4 \\
-2.5 \\
-3.9 \\
-3.4 \\
-. . \\
\end{array}$ \\
\hline
\end{tabular}

1 The values for glass, hard rubber, and marble, given in this table, differ slightly from the values given in a former paper, Determination of the edge correction in measurements of

values were in error, because the shield was placed too close to the specimen (about $3 \mathrm{~cm}$ ), 
Arrangements 4a (single specimen, large electrodes) and 5a (double specimen, large electrodes) yielded values which were in error by less than 1.5 percent except for titania VII which was in error by 3.8 percent. The other arrangements gave values of the dielectric constant which were too small by amounts varying from 2 to 7 percent.

Buchner ${ }^{10}$ tested arrangement $4 \mathrm{a}$ (single specimen, large electrodes), using eq 6 , by making measurements on sheets of potassium chloride (dielectric constant 4.68) of varying diameters and thicknesses. His measurements indicate that the error, if any, was small.

Grüneisen and Giebe ${ }^{11}$ tested arrangements $4 \mathrm{c}$ (single specimen, small electrodes) and 5c (double specimen, small electrodes), using eq 11 and 31, by measuring the dielectric constant of porcelain (dielectric constant 5.60), using sheets of various thicknesses. The conclusions reached in both the above researches are in substantial agreement with those of the present paper.

\section{(b) RECTANGULAR ELECTRODES}

Measurements were made on only two materials using rectangular electrodes. Specimens having high dielectric constants were not used because of the difficulty of getting them in the shape desired.

Theoretical equations were available for only four electrode arrangements aside from the guard-ring arrangement as was noted in part 1. The dielectric constants were computed by these equations, and the percentage errors computed, assuming the guard ring value to be correct, as was done for the circular electrodes. The results are given in table 3. As for circular electrodes, the number of specimens is the number of determinations for those arrangements using a single sheet of dielectric. Where two sheets of dielectric were required, the number of determinations was half the number of specimens. The length and width of the specimens are given for comparative purposes.

Arrangement $5 \mathrm{~b}$ (double specimens, center electrode small) gave values which were in error by less than 1 percent, and arrangement $4 \mathrm{a}$ (single specimen, large electrodes) gave values which were in error by less than 2.5 percent. The other arrangements gave errors as high as 14 percent. These errors are higher than for the analogous cases of circular electrodes with the exception of arrangement 5b (double specimen, center electrode small).

\section{DETERMINATION OF EMPIRICAL EQUATIONS}

A set of empirical equations for the computation of edge capacitances for both circular and rectangular electrodes was determined from the data used in testing the accuracy of the theoretical equations. The values of the edge capacitances, $C_{E}$ ( $C_{E}$ is here used as distinguished from $C_{e}$ which is used for the edge capacitance when vacuum is the dielectric), were determined for all the circular specimens listed in table 2 by subtracting the value of the guard-ring capacitance (corrected for the width of the gap between the guarded electrode and the guard electrode) from the value of the capacitance of each of the other arrangements where the electrode was the same diameter as that of the guarded electrode. The values of the edge capacitance per centi-

${ }_{10}$ A. Buchner, Measurements of dielectric constants, Z. tech. Physik. 16, 10 (1935).

$11 \mathrm{E}$. Grüneisen and $\mathrm{E}$. Giebe, Use of the three-plate capacitor for the determination of the dielectric constant fsolid bodies, Verhandl. deut. physik. Ges. 14, 921 (1912). 
TABLE 3.-Percentage error of dielectric constants computed by means of theoretical equations when rectangular electrodes were used

\begin{tabular}{|c|c|c|c|c|c|c|c|c|c|}
\hline 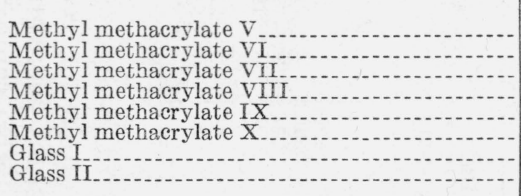 & $\begin{array}{r}c m \\
0.659 \\
.476 \\
.252 \\
.070 \\
.671 \\
.493 \\
.606 \\
.396\end{array}$ & $\begin{aligned} & c m \\
& 88 \\
& 88 \\
& 88 \\
& 63 \\
& 12 \\
& 12 \\
& 12 \\
& 12\end{aligned}$ & $\begin{array}{rr}c m & 9 \\
9 \\
9 \\
8 \\
11 \\
11 \\
12 \\
12\end{array}$ & $\begin{array}{l}4 \\
4 \\
4 \\
2 \\
2 \\
2 \\
2 \\
2\end{array}$ & $\begin{array}{l}3.25 \\
3.26 \\
3.19 \\
3.42 \\
3.25 \\
3.27 \\
7.65 \\
7.62\end{array}$ & $\begin{array}{r}-2.3 \\
-2.0 \\
-0.8 \\
-.6 \\
\hdashline\end{array}$ & $\begin{array}{r}-11.2 \\
-9.8 \\
-6.5 \\
-2.6 \\
-13.2 \\
-11.1 \\
-14.1 \\
-11.1\end{array}$ & $\begin{array}{r}+0.3 \\
+.0 \\
+.4 \\
\end{array}$ & $\begin{array}{r}-10.0 \\
-7.7 \\
-4.6 \\
-1.6 \\
-10.3 \\
-8.4 \\
-10.1 \\
-7.5\end{array}$ \\
\hline
\end{tabular}


meter of circumference, $C_{E} / P$ ( $P$ is the perimeter in centimeters) are given in table 4 .

The edge capacitances per centimeter for rectangular electrodes were determined by first measuring the capacitance with the guard electrode surrounding the small electrode, then measuring the capacitance after the portion of the guard electrode along the side had been removed but the guard electrodes left on the ends. This eliminated the effects of the ends and corners. The edge capacitances per centimeter for rectangular electrodes are given in table 5 .

TABLE 4.-Edge capacitance per centimeter of circumference of circular electrodes

\begin{tabular}{|c|c|c|c|c|c|c|}
\hline \multicolumn{3}{|l|}{ Electrode arrangement $\left\{\begin{array}{l}\mathrm{D} \\
\mathrm{F}\end{array}\right.$} & $4(b)$ & $\begin{array}{l}5(b) \\
5\end{array}$ & $\begin{array}{c}4(c) \\
4 \text { pres }\end{array}$ & $\frac{5}{5(c)}$ \\
\hline Material & $\begin{array}{l}\text { Thick- } \\
\text { ness }\end{array}$ & $\begin{array}{c}\text { Dielec- } \\
\text { tric } \\
\text { constant }\end{array}$ & \multicolumn{4}{|c|}{ Edge capacitance per centimeter } \\
\hline Polystyrene I.-. & $\begin{array}{l}c m \\
0.653\end{array}$ & 2.58 & $\stackrel{\mu \mu f}{0.165}$ & $\mu \mu f$ & $\mu \mu f$ & $\mu \mu f$ \\
\hline Polystyrene II... & .474 & 2. 57 & .171 & & .072 & \\
\hline Hard rub & .471 & 3.12 & .202 & 0.232 & .096 & 0.09 \\
\hline acrylate I. & .697 & 3.29 & .194 & .266 & .084 & .1 \\
\hline II. & .467 & 3.31 & .204 & 258 & .090 & \\
\hline E III. & .258 & 3.28 & .223 & 290 & .107 & 14 \\
\hline IV. & .081 & 3.32 & .269 & .327 & .136 & 2 \\
\hline $\mathrm{Ar}$ & .302 & 3.71 & .243 & & .107 & \\
\hline Cellulose acetate.-. & .312 & 5.14 & .289 & .428 & .133 & 2 \\
\hline Por & .597 & 6.19 & .324 & & .153 & \\
\hline & .467 & 7.76 & .385 & .620 & .177 & \\
\hline White marble. & .754 & 8.60 & .408 & .698 & .182 & 31 \\
\hline Blue marble.... & .703 & 8.75 & .412 & .730 & .179 & .33 \\
\hline Titania I.-. & .608 & 14.2 & 663 & & .321 & \\
\hline Titania II-- & .256 & 15.7 & .723 & & .365 & \\
\hline Titania III & .625 & 54.0 & 2.267 & & 1.094 & \\
\hline Titania IV & .589 & 57.4 & 2.385 & & 1.115 & \\
\hline Titania V...- & .554 & 57.0 & 2. 290 & & 1. 094 & \\
\hline VI & .249 & 57.1 & 2. 304 & & 1. 031 & \\
\hline Titania VII & .609 & 70. & 2. 927 & & 1. 141 & \\
\hline Titania VIII & .274 & 68.5 & 2. 863 & & $\begin{array}{l}1.427 \\
1.427\end{array}$ & \\
\hline Titania IX & .142 & 70.6 & 2. 979 & & 1.604 & \\
\hline
\end{tabular}

TABLE 5.-Edge capacitance per centimeter for rectangular electrodes

\begin{tabular}{|c|c|c|c|c|c|c|}
\hline \multicolumn{3}{|l|}{ Electrode arrangement $\left\{\begin{array}{l}\text { D } \\
F i\end{array}\right.$} & $4(b)$ & $\frac{5(b)}{5}$ & $\begin{array}{l}4(c) \\
\end{array}$ & $\begin{array}{c}5(c) \\
5(5)=0\end{array}$ \\
\hline Material & $\begin{array}{l}\text { Thick- } \\
\text { ness }\end{array}$ & $\begin{array}{l}\text { Dielec- } \\
\text { tric } \\
\text { constant }\end{array}$ & Ed & ge capacitanc & e per centim & eter \\
\hline 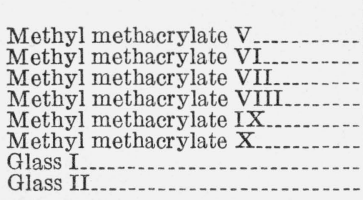 & $\begin{array}{l}c m \\
0.659 \\
.476 \\
.252 \\
.070 \\
.671 \\
.493 \\
.606 \\
.396\end{array}$ & $\begin{array}{l}\text { 3. } 25 \\
\text { 3. } 26 \\
3.19 \\
3.42 \\
\text { 3. } 25 \\
3.27 \\
7.65 \\
7.62\end{array}$ & $\begin{array}{r}\mu \mu f \\
0.181 \\
.194 \\
.211 \\
.270 \\
.186 \\
.193 \\
.376 \\
.376\end{array}$ & $\begin{array}{l}\mu \mu f \\
0.261 \\
.266 \\
.273 \\
-2 \\
-\end{array}$ & $\begin{array}{c}\mu \mu f \\
0.078 \\
.085 \\
.099 \\
.138 \\
.081 \\
.084 \\
.167 \\
.171\end{array}$ & $\begin{array}{r}{ }_{\mu} \mu f \\
0.135 \\
.132 \\
.156 \\
\hdashline \\
\hdashline\end{array}$ \\
\hline
\end{tabular}

The effect that a corner had on the edge capacitance was determined by measuring the edge capacitance for rectangular electrodes when the guard electrode along the sides was removed and again when the guard electrode at the ends was also removed. The edge capacitance 
per centimeter of length was computed from the value of edge capacitance obtained when the guard electrode along the side had been removed. The total capacitance due to the edge was computed by multiplying the capacitance per centimeter by the perimeter. The difference between the total measured edge capacitance and the computed edge capacitance gave the effect of the corners. The capacitances due to the corners are given in table 6. From this it is discovered that within experimental error the corner has a negligible effect for all of the electrode arrangements.

TABLE 6.-Capacitance of corners of rectangular electrodes

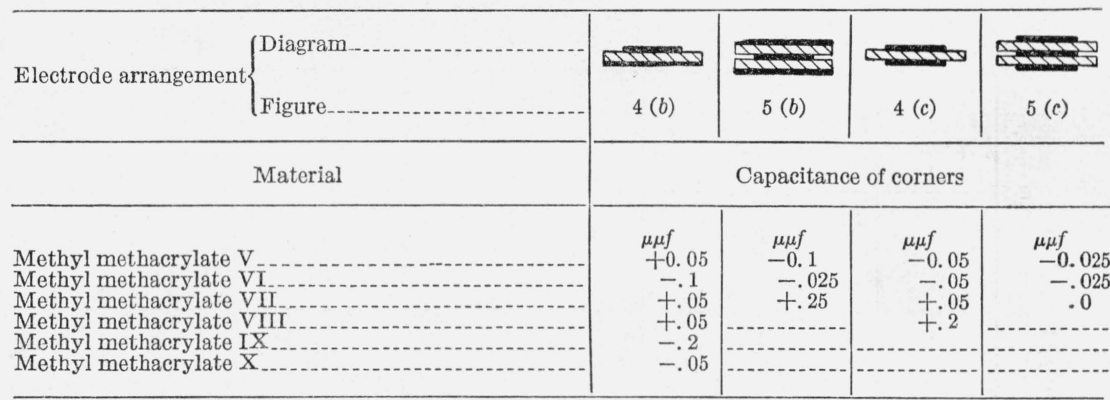

The results in tables 4 and 5 show that there is little if any difference between the edge capacitances per centimeter for circular and rectangular electrodes. The fact that the corners have little effect on the edge capacitance should lead one to expect this agreement.

Since the capacitances per centimeter are the same for circular as for rectangular electrodes, it was possible to set up a single set of empirical equations for computing the dielectric constant. The equations apply equally well to both rectangular and circular electrodes.

The results in tables 4 and 5 also show that, for anylarrangement of electrodes the edge capacitance depends both on the dielectric constant of the material and on the thickness of the specimen. In order to construct an empirical equation involving both these? variables, the effect of each separately was determined. The effect of the dielectric constant of the material on the edge capacitance was determined by selecting a group of samples all of which had about the same thickness. The data for this group (for both circular and rectangular electrodes) are shown in figure 7. The edge capacitances per centimeter of circumference, $C_{E} / P$, are plotted against the dielectric constant for arrangements $4 \mathrm{~b}$ (single specimen, one electrode small) and $4 \mathrm{c}$ (single specimen, small electrodes).

It is quite clear that the points lie on a straight line and that this line extended does not pass through the origin. This indicates that the relationship between the edge capacitance, $\mathrm{C}_{E}$, and the dielectric constant for a given thickness can be expressed as the sum of two terms, one of which, $C_{m}$, is directly proportional to the dielectric constant, while the other, $C_{\imath}$, has a value that is given by the intercept on the axis of zero dielectric constant.

In order to develop the empirical equations, it was assumed that the slopes of the lines in figure 7 do not change with thickness of the 
specimens, that is, that the part, $C_{m}$, of the edge capacitance which is a function of the dielectric constant does not change with thickness of the specimen. From the slopes of the lines it was determined that for arrangement $4 \mathrm{~b}$ (single specimen, one electrode small)

$$
\frac{C_{m}}{P}=0.0405 K
$$

and for arrangement $4 \mathrm{c}$ (single specimen, small electrodes)

$$
\frac{C_{m}}{P}=0.185 K
$$

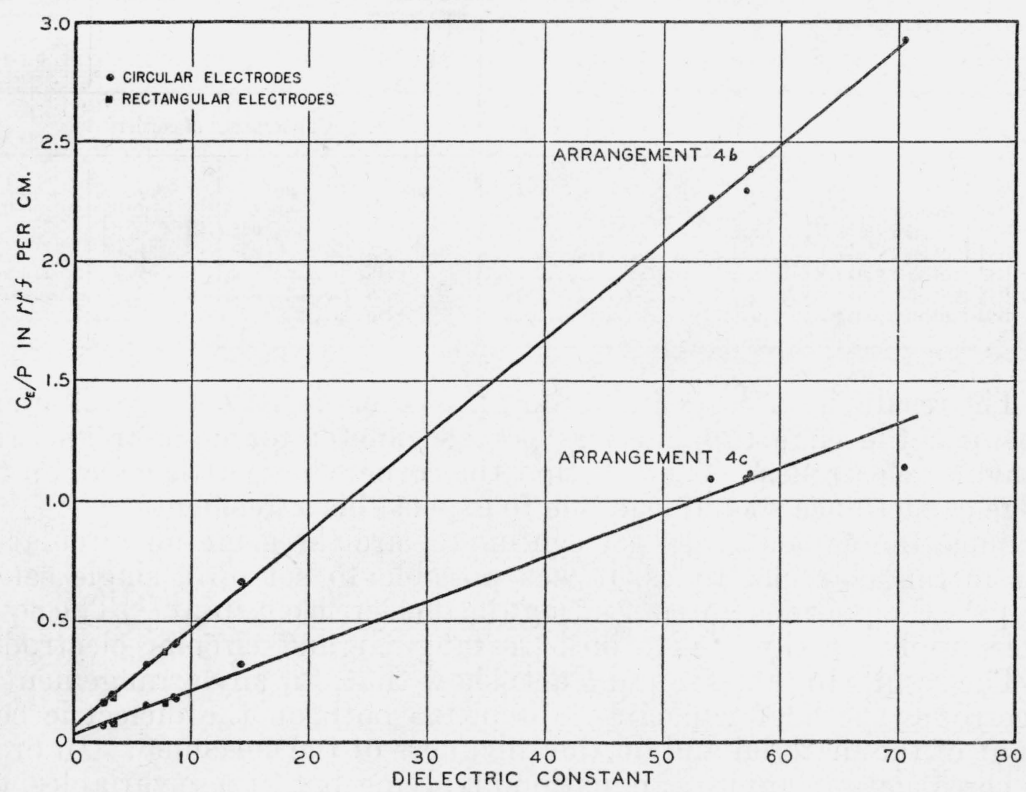

Figure 7.-Relation, for circular electrodes, between the edge capacitane $C_{E}$ and the dielectric constant.

Arrangement $4 \mathrm{~b}$ is a single specimen with one electrode smaller than the other. Arrangement $4 \mathrm{c}$ is a single specimen with both electrodes small.

Since the dielectric constants of the specimens listed in tables 4 and 5 were determined with the guard electrode, the values of $C_{m} / P$ for these specimens could be computed.

The value of the portion, $C_{i} / P$, of the edge capacitance per centimeter of circumference, which was independent of the dielectric constant, was obtained for each specimen by subtracting the value of $C_{m} / P$ from the value of $C_{E} / P$, given in tables 4 and 5 . These values of $C_{i} / P$ for the specimens having dielectric constants less than 9 are plotted in figure 8 against the logarithm of the thickness of the specimen. The values of $C_{i} / P$ for the specimens of higher dielectric constant were not used, because the values of $C_{i}$ become relatively less important, as compared to the total capacitances of the specimens, as the dielectric constant increases. The points of figure 8 fall along straight lines, showing that $C_{i} / P$ is a linear function of the logarithm 
of the thickness. The relationship for arrangement $4 \mathrm{~b}$ (single specimen, one electrode small) is

$$
\frac{C_{i}}{P}=\frac{1}{30} \ln \frac{3.8}{b},
$$

and for arrangement $4 \mathrm{c}$ (single specimen, small electrodes) is

$$
\frac{C_{i}}{P}=\frac{1}{40} \ln \frac{1.5}{b} \text {. }
$$

The ability to make the separation of the edge capacitance into two parts, one of which is a function of the dielectric constant of the material and the other independent of it, indicates a superiority of

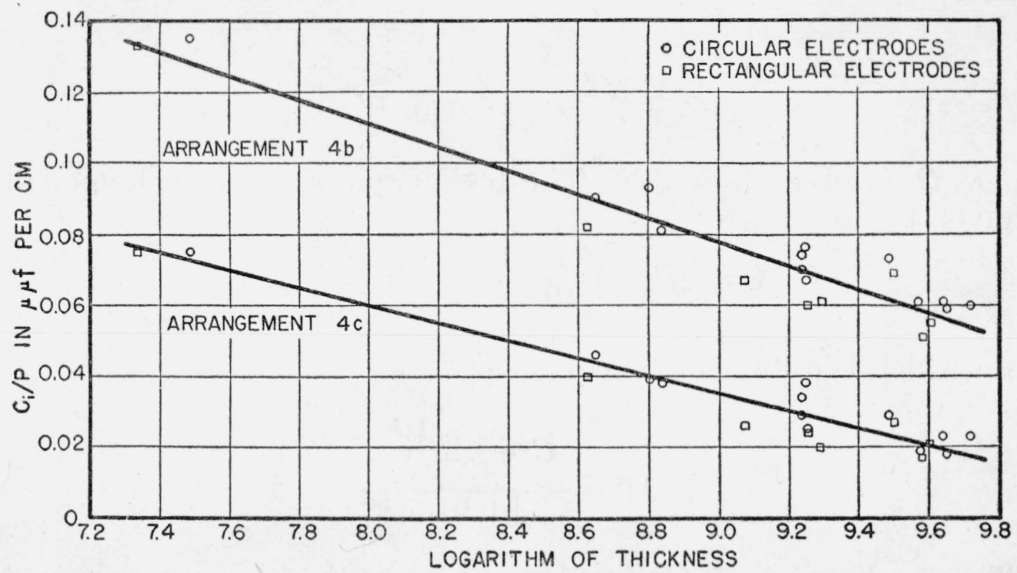

FIGURE 8.-Relation, for circular electrodes, between the edge capacitance which is not a function of the dielectric constant, $C_{i}$, and the thickness of the specimen

Arrangement $4 \mathrm{~b}$ is a single specimen with one electrode smaller than the other. Arrangement $4 \mathrm{c}$ is a single specimen with both electrodes small.

this method over any of the theoretical methods for determining edge corrections. The theoretical equations cannot make this separation, because they were derived on the assumption that the field at the edge was all in a uniform dielectric. This, as well as the direction of the error due to nonfulfillment of the assumption, was pointed out in part 1.

Equations for the edge capacitances of arrangements $4 \mathrm{~b}$ and $4 \mathrm{c}$ can now be set up. The edge capacitance for arrangement $4 \mathrm{~b}$ (single specimen, one electrode small) is given by

$$
C_{E}=C_{\imath}+C_{m}=\left(\frac{1}{30} \ln \frac{3.8}{b}+.0405 K\right) P,
$$

where $P$ is the perimeter of the small electrode in $\mathrm{cm}, b$ is the thickness in centimeters, and $K$ is the dielectric constant. The edge capacitance for arrangement 4c (single specimen, small electrodes) is given by

$$
C_{E}=C_{i}+C_{m}=\left(\frac{1}{40} \ln \frac{1.5}{b}+.0185 K\right) P .
$$


It should be pointed out that eq 42 and 43 were developed from data obtained with electrodes having a diameter of $11.0 \mathrm{~cm}$ and a thickness of $0.003 \mathrm{~cm}$. However, they will apply in most practical applications because $11 \mathrm{~cm}$ is within a few percent of what has practically become a standard diameter, and $0.003 \mathrm{~cm}$ is the thickness of the tinfoil which is generally used for electrode material.

It is now possible to set up accurate equations for the computation of the dielectric constant for arrangements $4 \mathrm{~b}$ (single specimen, one electrode small) and 4c (single specimen, small electrodes). The total capacitance of a specimen having a circular electrode arrangement $4 \mathrm{~b}$ is given by

Hence,

$$
\boldsymbol{C}=K C_{n}+\left(\frac{1}{30} \ln \frac{3.8}{b}+.0405 K\right) P .
$$

$$
K=\frac{C-\frac{P}{30} \ln \frac{3.8}{b}}{C_{n}+0.0405 P}
$$

where $C_{n}$ is given by eq 2 . The total capitance for arrangement $4 \mathrm{c}$ is given by

$$
\boldsymbol{C}=K C_{n}+\left(\frac{1}{40} \ln \frac{1.5}{b}+0.0185 K\right) P,
$$

from which is obtained the equation

$$
K=\frac{C-\frac{P}{40} \ln \frac{1.5}{b}}{C_{n}+0.0185 P} .
$$

The evaluation of $C_{i}$ for arrangement $4 \mathrm{~b}$ (single specimen one electrode small) makes it possible to determine the equation for the dielectric constant for arrangement $5 \mathrm{~b}$ (double specimen, center electrode small). If it is assumed that $C_{i}$ is the part of the edge capacitance arising from the electric field in the air, then facing two specimens of arrangement $4 \mathrm{~b}$ (single specimen, one electrode small) together to form arrangement $5 \mathrm{~b}$ eliminates $C_{i}$, since the center electrode is practically completely surrounded by dielectric.

The value of $C_{m}$ for the double specimen should be twice that for a single specimen, and $C_{n}$ should be the sum of the values for the individual specimens. The equation for arrangement $5 \mathrm{~b}$ would then be

$$
K=\frac{C}{\mathrm{C}_{n 1}+C_{n 2}+0.081 P},
$$

where $C_{n 1}$ and $C_{n 2}$ are the values of $C_{n}$ for the single specimens making up the double specimen.

As noted in part 1, the theoretical equation (eq 28) for this arrangement gave values that were in error by less than 0.6 percent. This equation has the same form as eq 48 except that the coefficient of $P$ is 0.0782 rather than 0.081 .

An equation for the dielectric constant for arrangement $5 \mathrm{c}$ (double specimen, small electrodes) can be obtained in the same way as for 
arrangement 5b. Facing together two specimens of arrangement $4 \mathrm{c}$ (single specimen, small electrodes) eliminated $C_{t}$. The value of $C_{m}$ for the double specimen should be twice that for the single specimen, and the value of $C_{n}$ for the double specimen should be the sum of those for the single specimens. Thus for arrangement $5 \mathrm{c}$

$$
K=\frac{C}{C_{n 1}+C_{n 2}+0.037 P} .
$$

This equation has the same form as the theoretically derived equation (eq 32), but the coefficient of $P$ in the theoretical equation is 0.0625 instead of 0.037 .

The equation for the dielectric constant for arrangement $4 \mathrm{a}$ (single specimen, large electrodes) was obtained from eq 46 for arrangement 4c (single specimen, small electrodes). For arrangement 4a the edge capacitance was all assumed to be in air; therefore the dielectric constant in the term for edge capacitance became unity. Thus for arrangement $4 \mathrm{a}$

$$
K=\frac{C-\left(\frac{1}{40} \ln \frac{1,5}{b}+0.0185\right) P}{C_{n}} .
$$

The equation for the dielectric constant for arrangement $5 \mathrm{a}$ (double specimen, large electrodes) was obtained from eq 49 for arrangement $5 \mathrm{c}$ (double specimen, small electrodes). Assuming the edge capacitance for arrangement $5 \mathrm{a}$ all to be in air, the dielectric constant in the edge capacitance term was taken as unity. Thus, for arrangement 5a

$$
K=\frac{C-0.037 P}{C_{n 1}+C_{n 2}} .
$$

The theoretical equation given for this arrangement (eq 22) has the same form as eq 51, but the coefficient of $P$ was 0.0625 instead of 0.037 .

\section{DIELECTRIC CONSTANTS WHEN EMPIRICAL EQUATIONS WERE USED}

The dielectric constants of all the specimens listed in tables 2 and 3 were recomputed using the empirical equations which are given above. The results for circular electrodes are given in table 7 , and for rectangular electrodes in table 8.

In only one case is the error greater than 1.0 percent. For circular electrodes five-sixths of the results have errors 0.5 percent or less, whereas one-sixth of them have errors less than 0.1 percent. For rectangular electrodes three-fourths of the results have errors of 0.5 percent or less, whereas one-fifth of them have errors less than 0.1 percent.

The one case where the error was greater than 1 percent was that for titania VII having a dielectric constant of 70.5 when arrangement 4a (single specimen, large circular electrodes) was used. This large error (3.8 percent) can probably be explained, since the edges of this disk: were rather irregular, and therefore the area of the electrodes 
was not the same as for the specimen. The great disadvantage of arrangements 4a (single specimen, large electrodes) and 5a (double specimen, large electrodes) is the difficulty of preparing the specimens so that they have good sharp edges, and thus making sure that the electrodes come exactly to the edge of the specimen. For this reason these arrangements are not as easily used as the other arrangements.

These results indicate that rectangular electrodes can be as readily used as circular electrodes and will give as much accuracy. The effect of the corners can be ignored.

TABLE 7.-Percentage error of dielectric constants computed by means of empirical equations when circular electrodes were used

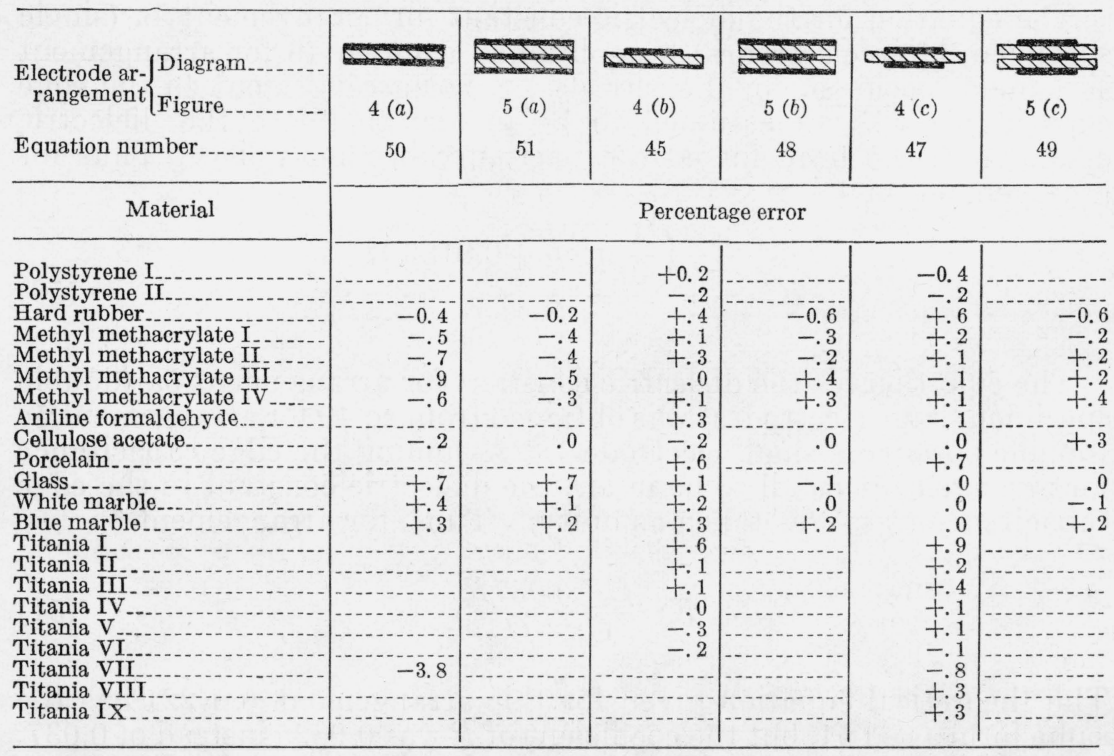

TABLE 8.-Percentage error of dielectric constants computed by means of empirical equations when rectangular electrodes were used

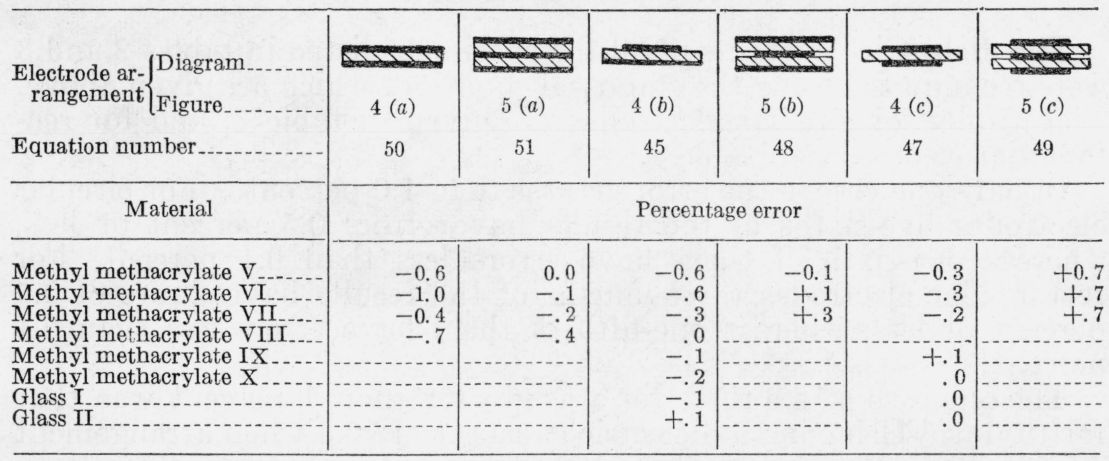

The method which is the easiest to use and which will therefore give the most accurate results in general is arrangement $4 \mathrm{~b}$ (single specimen, one electrode large) using eq 45 . Since one electrode is smaller than the other, no great care is needed for centering the 
electrodes. On the other hand, great care must be taken with arrangement 4c (single specimen, small electrodes) and 5c (double specimen, small electrodes) to see that the two electrodes on each specimen are opposite each other, and this is sometimes quite difficult. Arrangement 5b (double specimen, center electrode small) is somewhat difficult to use because it is necessary that the two electrodes which are faced together should be exactly opposite each other when the two specimens are placed together to make the double specimen. Also, correction must be made for the capacitance of that part of the lead to the center electrode which is between the larger electrodes, as this cannot be shielded without disturbing the field. However, these difficulties can be overcome with care, and this method has the great advantage that the unit is practically a shielded capacitor. By connecting the outer electrodes to the low potential side of the bridge, the high potential electrode is completely shielded. This allows a number of test units to be stacked on each other without interference between them.

\section{SUMMARY}

The theoretical equations given in part I all had edge corrections which overcorrected for the edge capacitance except eq 28 for circular electrodes and eq 33 for rectangular electrodes. Both of these equations apply to the electrode arrangement for a pair of specimens where the center electrode is smaller than the other two, and both gave values of the dielectric constant which were in error by less than 1 percent.

Kirchhoff's equation for the capacitance between two circular disks of the same diameter and thickness was found to be correct within experimental error.

Empirical equations were set up which gave values that were in error by less than 1 percent for all electrode arrangements and which were simpler than most of the theoretical equations.

Electrode arrangements which have electrodes extending to the edge of the specimen are very difficult to use because of the difficulty of preparing the specimens with good sharp edges and fixing the electrodes so that they extend exactly to the edges.

The most accurate method for the determination of the dielectric constant, aside from the guard-ring method, is that using one specimen and having one electrode appreciably smaller than the other. Part of the accuracy is due to the fact that the electrodes do not have to be accurately centered on the specimen.

The arrangement consisting of a double specimen with a center electrode smaller than the outer electrodes gives accurate values if the small electrodes of the two single specimens making up the double specimen are exactly opposite each other. This is somewhat difficult, but with care this can be accomplished, and this arrangement has the advantage that the center electrode is completely shielded by the outer electrodes, which may be connected to the low-potential side of the bridge for measurement. Such test units can be stacked without interference between them.

Washington, March 14, 1939. 